\title{
Prolonged, low-grade inflammation in the first week of lactation: Associations with mineral, protein, and energy balance markers, and milk yield, in a clinically healthy Jersey cow cohort
}

\author{
L. F. Martins, ${ }^{1}$ P. R. Menta, ${ }^{2}$ L. Fernandes,${ }^{2}$ V. S. Machado, ${ }^{2}$ and R. C. Neves ${ }^{1 *}$ \\ ${ }^{1}$ Department of Veterinary Clinical Sciences, College of Veterinary Medicine, Purdue University, West Lafayette, IN 47907 \\ ${ }^{2}$ Department of Veterinary Sciences, Texas Tech University, Lubbock 79409
}

\begin{abstract}
Our objectives were to perform a proof-of-concept study to assess the association of a prolonged inflammatory state (based on a continually elevated haptoglobin concentration at the end of the first week after parturition) with mineral, protein, and energy balance markers in the first 2 wk after parturition, and milk production in the first $60 \mathrm{~d}$ of lactation in clinically healthy cows. We conducted a cohort study in 1 herd in west Texas that was milking Jersey and Jersey-Holstein crosses. Only multiparous Jersey cows were eligible for enrollment. Cows were classified as having or not having elevated haptoglobin concentrations based on plasma concentrations evaluated on d 4 and 7 postpartum. We used median concentrations of haptoglobin in the reference population (i.e., before the exclusion of cows diagnosed with clinical diseases) as the limits for categorizing cows into 2 groups: cows with plasma haptoglobin concentrations greater than the median values on both d $4(0.49 \mathrm{~g} / \mathrm{L})$ and $7(0.35 \mathrm{~g} / \mathrm{L})$ had continually elevated haptoglobin (with $\mathrm{eHp}$ ); and cows with plasma haptoglobin concentrations lower than or equal to the median values of the reference population on $\mathrm{d} 4$ or 7 did not have continually elevated haptoglobin (without eHp). Next, cows with clinical diseases in the first 2 wk of the postpartum period were excluded, so that 233 cows remained for the final analyses. Evaluated outcomes were average daily milk production across the first $60 \mathrm{~d}$ of lactation, plasma $\mathrm{Ca}, \mathrm{Mg}$, and glucose concentrations on $\mathrm{d} 1,2,3,4,5,7,10$, and 14 postpartum, and $\beta$-hydroxybutyrate (BHB), nonesterified fatty acids (NEFA), fructosamine, albumin, urea, and creatinine concentrations on d 3, 5, 7, 10, and 14 postpartum. Rectal temperatures measured on d 4, 7 , and 10 postpartum were also analyzed. We performed
\end{abstract}

Received August 27, 2020.

Accepted December 12, 2020.

*Corresponding author: rcneves@purdue.edu statistical analyses using linear mixed models while accounting for the repeated effect of sampling time (plasma analytes and rectal temperature models) and weekly milk test (milk production model). Cows with eHp had lower plasma Ca concentrations in the first 2 wk after calving, but no differences in $\mathrm{Mg}$, BHB, NEFA, glucose, or rectal temperatures compared to cows without eHp. Cows with eHp had lower plasma fructosamine, albumin, and urea concentrations in a time-dependent manner. They also had lower milk production $(2.3 \mathrm{~kg} / \mathrm{d}$ less than cows without $\mathrm{eHp}$ in the first 60 DIM). Our study demonstrated that $25 \%$ of cows without clinical disorders in the first $2 \mathrm{wk}$ after parturition had continually elevated haptoglobin concentrations at $\mathrm{d} 7$ after parturition relative to $\mathrm{d} 4$, suggestive of a prolonged, low-grade systemic inflammatory state. More observational studies are needed to more fully characterize the duration of prolonged postpartum subclinical inflammation in cows without clinical diseases, as well as its long-term effects, and to evaluate the use of other potential markers of systemic inflammation to describe this disorder.

Key words: subclinical inflammation, calcium, energy balance, milk production

\section{INTRODUCTION}

Inflammation is a process involved in parturition that may influence the adaptive process of lactation by aiding in nutrient partitioning to support milk production via insulin resistance (Farney et al., 2013). Moreover, several proinflammatory cytokines are upregulated at parturition and are associated with normal events at parturition such as cervical dilation, rupture of fetal membranes, and myometrial contractility (Challis et al., 2009; van Engelen et al., 2009). Importantly, an orchestrated inflammatory response in the immediate postpartum period is key to supporting uterine involution and pathogen clearance (Bradford et al., 2015). The resolution of inflammation is also an integral part of the inflammatory response, orchestrated in the first 
few hours after the stimuli (Serhan and Savill, 2005). In dairy cows, an impaired inflammatory response is associated with health disorders such as retained placenta (Dervishi et al., 2016), metritis (Huzzey et al., 2009), and ketosis (Abuajamieh et al., 2016).

Haptoglobin is a positive acute-phase protein commonly used as a marker of systemic inflammation (Ceciliani et al., 2012). Some observational studies found an association between increased serum (or plasma) haptoglobin measured at a single time point in the first week postpartum and lower milk production (Huzzey et al., 2015; McCarthy et al., 2016; Shin et al., 2018). Nightingale et al. (2015) found a reduction in the reproductive efficiency of clinically healthy cows with increased blood haptoglobin following parturition. Good evidence is available showing that the degree of inflammation in early postpartum is associated with detrimental production outcomes. However, we are not aware of any studies that have aimed to determine whether the rate of resolution of postpartum inflammation is associated with the metabolism and performance of cows.

Inflammation can alter the energy and mineral balance of cows. Using an induction model of acute inflammation, Kvidera et al. (2017) demonstrated that euglycemia could be maintained in lactating cows only when exogenous glucose supply was more than $1 \mathrm{~kg}$ within 720 min after an LPS challenge. Intravenous administration of LPS resulted in hypocalcemia in dairy cows (Horst et al., 2020). Daily injections of tumor necrosis factor- $\alpha$ (TNF- $\alpha$; a proinflammatory cytokine) over a 7 -d period (i.e., repeated inflammatory insults) in cows in late lactation increased liver triglyceride accumulation (Bradford et al., 2009). Using a similar model, Yuan et al. (2013) failed to demonstrate any effects of repeated TNF- $\alpha$ administration in systemically altering concentrations of energy metabolites such as glucose, $\mathrm{BHB}$, and nonesterified fatty acids (NEFA), despite a reduction in DMI and milk production. Observational studies investigating the association between lengthier inflammatory resolution in cows in the postpartum period and concentrations of glucose, NEFA, and BHB (energy balance markers) and $\mathrm{Ca}$ are needed and can shed more light on the association between inflammation resolution and metabolic disorders in a more natural framework.

In cows without clinical diseases in early lactation, sufficient evidence exists demonstrating that haptoglobin normally achieves peak concentration within the first 3 d after parturition (Huzzey et al., 2009; Trevisi et al., 2010; Trevisi et al., 2012; Caré et al., 2018; Mezzetti et al., 2019). In a haptoglobin kinetics study using an intramammary challenge with Escherichia coli, peak concentrations occurred at $72 \mathrm{~h}$ post-challenge. More- over, the half-life decay rate (i.e., the time required for haptoglobin to achieve half of its peak concentration) was $46 \mathrm{~h}$ and the mean residence time (i.e., a calculation of the time a molecule resides in the body) was 112 h (i.e., 4 d and 16 h; Salonen et al., 1996). Considering that inflammation is a biological process at the onset of lactation (driven by parturition) and that a maladaptive process impairs the performance and health of cows, we assumed that the evaluation of haptoglobin concentrations toward the end of the first week of parturition and the use of 2 sampling time points, d 4 (i.e., closely after the haptoglobin's peak concentration that occurs approximately $72 \mathrm{~h}$ post-calving) and $\mathrm{d} 7$ after parturition (i.e., a follow-up sample $3 \mathrm{~d}$ after the initial assessment to encompass the haptoglobin's half-life decay period of $46 \mathrm{~h}$ ), would allow us to better investigate the state of postpartum inflammatory resolution in cows; this classification scheme would more likely resemble a persistent inflammatory state. Our objectives were to perform a proof-of-concept study to evaluate the association between a maladaptive postpartum inflammatory state and milk production, and to compare mineral, protein, and energy balance markers in the first 2 wk after parturition in cows with a more prolonged systemic inflammatory state using a well-characterized cohort of cows without clinical disorders.

\section{MATERIALS AND METHODS}

\section{Study Design and Study Population}

All procedures involving animals were approved by the Texas Tech University Institutional Animal Care and Use Committee (protocol 18035-04). A cohort study was conducted in a commercial dairy farm in west Texas that was milking 3,800 Jersey and JerseyHolstein crosses; cow enrollment occurred from July to December 2018.

Only multiparous Jersey cows were enrolled. Animals were housed in a dry lot system and were milked and fed a TMR twice daily. Sample size was calculated to detect a difference of at least $2.0 \mathrm{~kg}$ of milk per day [standard deviation $(\mathrm{SD})=4.5 \mathrm{~kg}$ ] between cows with a more prolonged inflammatory state and cows without, assuming a $25 \%$ incidence of systemic inflammation in the cohort. For a study with $80 \%$ power and $\alpha$ at 0.05 , a total of 215 cows was necessary.

\section{Data Collection}

The research group visited the farm daily at the same time of day (0800 h) from July to December 2018, and collected blood samples from the cows at 1, 2, 3, 4, 5, 7, 10, and 14 DIM. Blood samples were collected by coc- 
cygeal venipuncture using a 20-gauge $\times 2.54 \mathrm{~cm}$ needle into $9 \mathrm{~mL}$ vacutainer tubes containing spray-dried lithium heparin (Greiner Bio-One, Monroe, NC). Tubes were gently inverted to allow proper anticoagulant mixing and immediately placed in a thermo-conductive, passive-temperature-regulating module (CoolRack; BioCision, San Rafael, CA) which was kept inside a cooler containing ice water and transported to Texas Tech University (Lubbock) within $2 \mathrm{~h}$ after collection for processing. Samples were centrifuged at $1,200 \times g$ for $15 \mathrm{~min}$ and plasma was stored at $-80^{\circ} \mathrm{C}$ until further analyses.

Weekly milk yield was collected by the research personnel using a hand-held data entry system and automatically downloaded into DairyComp 305 (Valley Agricultural Software, Tulare, CA) for the duration of the data collection period. Disease event data were recorded by farm personnel in DairyComp 305 using disease definition protocols set before the start of the study. Retained placenta was defined as the failure to expel fetal membranes after $12 \mathrm{~h}$ of parturition; displaced abomasum was defined as a classical resonant sound during concurrent auscultation and percussion of the left or right flank region; clinical mastitis was defined as visibly abnormal milk, local changes in the udder (i.e., swelling, heat, pain), or both; dystocia was defined as the inability of the dam to deliver the calf without human intervention. Metritis was diagnosed by 1 trained research staff member at 4, 7, and 10 DIM using a Metricheck device (Simcro, Hamilton, New Zealand). Vaginal discharge was scored based on a modified scale of 1 to 5: 1 = clear mucoid discharge with no smell; 2 = cloudy and mucoid discharge with no smell; $3=$ mucopurulent discharge with $<50 \%$ pus and no smell; $4=$ mucopurulent discharge ranging in white, yellowish to red-brownish color with $\geq 50 \%$ pus and not fetid; 5 = fetid, thin, serous or watery, red-brownish discharge with or without pieces of necrotic tissues present (de Oliveira et al., 2020). Cows with a score of 5 were classified as having metritis. One trained research staff member evaluated BCS at 4 DIM using a 5-point scale (Ferguson et al., 1994).

Samples collected at 3, 5, 7, 10, and 14 DIM were analyzed for total $\mathrm{Ca}$, total $\mathrm{Mg}$, glucose, NEFA, BHB, albumin, fructosamine, urea, and creatinine. Samples collected at 1, 2, and 4 DIM were analyzed for total Ca, total $\mathrm{Mg}$, and glucose, and samples collected at 4 and 7 DIM were analyzed for haptoglobin levels. Except for haptoglobin, all analytes were measured in an automated clinical chemistry analyzer (RX Daytona; Randox Laboratories Ltd., Crumlin, UK) using reagents supplied by the manufacturer. Calibrations followed the manufacturer's recommendations and quality-control checks were performed daily before sample analyses.
Intra- and inter-assay coefficients of variation were as follows: 2.4 and $3.3 \%$ for total $\mathrm{Ca} ; 2.8$ and $2.6 \%$ for total $\mathrm{Mg} ; 1.8$ and $3.9 \%$ for glucose; 0.7 and $1.8 \%$ for nonesterified fatty acids (NEFA); 1.0 and $1.4 \%$ for BHB; 1.3 and $2.4 \%$ for albumin; 1.5 and $2.4 \%$ for fructosamine; 1.7 and $2.0 \%$ for urea; and, 2.8 and $4.0 \%$ for creatinine, respectively.

Plasma haptoglobin concentrations were determined using a non-commercial colorimetric assay and quantifying the haptoglobin-hemoglobin complex by estimating differences in peroxidase activity (Makimura and Suzuki, 1982). Assays were performed in $16 \times 100 \mathrm{~mm}$ borosilicate tubes; briefly, $5 \mu \mathrm{L}$ of sample, deionized water (blank), or standard were added to $7.5 \mathrm{~mL}$ of a solution containing $0.6 \mathrm{~g} / \mathrm{L}$ of $o$-dianisidine, $13.8 \mathrm{~g} / \mathrm{L}$ of sodium phosphate monobasic, and $0.5 \mathrm{~g} / \mathrm{L}$ EDTA (pH $=4.1$ ). Next, $25 \mu \mathrm{L}$ of a solution containing $0.3 \mathrm{~g} / \mathrm{L}$ bovine hemoglobin was added to each tube, followed by water-bath incubation at $37^{\circ} \mathrm{C}$ for $45 \mathrm{~min}$. Next, 100 $\mu \mathrm{L}$ of a freshly prepared $156 \mathrm{~m} M$ hydrogen peroxidase solution was added to each tube and incubated at room temperature for $60 \mathrm{~min}$. Then, $200 \mu \mathrm{L}$ of each tube was transferred to a 96-well plate and the optical density read at $450 \mathrm{~nm}$ in an Epoch2 Microplate Spectrophotometer (BioTek Instruments Inc., Winoosk, VT). Standard curves were generated by serial dilution of a known concentration haptoglobin stock sample as previously validated by Machado et al. (2020). Intra- and inter-assay coefficients of variation were 5.2 and $7.3 \%$, respectively.

\section{Systemic Inflammation Classification and Statistical Analyses}

Haptoglobin is associated with clinical diseases. Because our objective was to investigate the effects of maladaptive systemic inflammatory status in cows with prolonged, low-grade (i.e., subclinical) inflammation, all cows with 1 or more clinical disorders diagnosed within 14 DIM that could affect haptoglobin concentrations on d 4 and 7 after calving were excluded. Exclusion criteria included cows with retained placenta $(\mathrm{n}=$ $3)$, milk fever $(\mathrm{n}=3)$, displaced abomasum $(\mathrm{n}=3)$, metritis $(\mathrm{n}=94)$, and clinical mastitis within 14 DIM $(\mathrm{n}=13)$. In addition, cows that had a gestation length less than $260 \mathrm{~d}$ (considered an abortion; $\mathrm{n}=1$ ), had dystocia $(\mathrm{n}=5)$, had a stillbirth $(\mathrm{n}=4)$, were culled within 14 DIM $(\mathrm{n}=2)$, had a missing Metricheck score $(\mathrm{n}=9)$, or had rectal temperatures $\geq 39.5^{\circ} \mathrm{C}$ (fever; $\mathrm{n}$ $=7$ ) at 4 , or 7 , or 10 DIM were also excluded. In total, 233 cows remained for the final analyses.

Before any cow exclusion (i.e., all cows sampled; reference population), we determined the distribution of haptoglobin concentrations on d 4 and 7 after parturi- 
tion and used the median concentrations on those days (0.49 and $0.35 \mathrm{~g} / \mathrm{L}$, respectively) to classify cows according to 2 systemic inflammation categories. Cows with clinical diseases were excluded, as previously detailed, and those without clinical diseases were retrospectively categorized as follows: cows with plasma haptoglobin concentrations greater than the median values from the reference population on both $\mathrm{d} 4$ and 7 after parturition were considered to have continually elevated haptoglobin concentrations (with eHp), suggestive of a prolonged inflammatory state; and cows with plasma haptoglobin concentrations lower than or equal to the median values from the reference population on days 4 or 7 after parturition did not have continually elevated haptoglobin concentrations (without eHp), suggestive of a more balanced postpartum inflammatory state.

Evaluated outcomes were average milk production across the first 10 wk of lactation; plasma $\mathrm{Ca}, \mathrm{Mg}$, and glucose concentrations on d 1, 2, 3, 4, 5, 7, 10, and 14 postpartum; and BHB, NEFA, fructosamine, albumin, urea, and creatinine concentrations evaluated on d 3 , $5,7,10$, and 14 postpartum according to categorized inflammatory status. We also evaluated the association of inflammatory status with rectal temperatures measured on $\mathrm{d} 4,7$, and 10 postpartum.

Before statistical analyses, we set categories for parity (cows in their 2 nd versus $3 r d$ or greater lactations), BCS [thin $(\mathrm{BCS} \leq 2.75)$, normal $(3.0 \leq \mathrm{BCS} \leq 3.5)$, or overconditioned (BCS $\geq 3.75)]$, and calving season [warmer months (July 16 to September 22, 2018) versus cooler months (September 23 to December 9, 2018)]. Hourly dry bulb and dew point temperature records were retrieved from the closest meteorological station to the herd in the study $(35 \mathrm{~km}$; National Oceanic and Atmospheric Administration, US Department of Commerce, Silver Spring, MD) to calculate average temperature-humidity indexes for each calving season according to Yousef (1985). Mean temperature-humidity indexes for the warmer and cooler months were 72.3 $(\mathrm{SD}=4.8)$ and $54.0(\mathrm{SD}=10.2)$, respectively.

All statistical analyses were performed in SAS version 9.4 (SAS Institute Inc., Cary, NC). Descriptive statistics were carried out using the UNIVARIATE and FREQ procedures. Linear mixed models accounting for the repeated effect of sampling time (for plasma analytes and rectal temperature models) and weekly milk test (milk production model) were performed using the MIXED procedure. Potential covariates included in all models were inflammatory status (i.e., predictor of interest), parity, season, BCS category, and time. Clinical mastitis diagnosis between 15 and 60 DIM was considered a confounder a priori in the milk production model. Culling between 15 and 60 DIM was accounted for in the milk production model to better isolate the effect of inflammatory status while allowing culled cows to contribute to the analysis with milk weights that happened before the culling event. Models were built using a backward stepwise selection procedure. Variables with $P>0.10$ were retained in the final model if they were a confounder of other significant variables or the predictor of interest (i.e., $>20 \%$ effect on model estimates). Two-way interactions between the inflammatory status variable, parity, and time were tested in the final models and retained if significant at $P \leq 0.05$. Four covariance structures were tested in the final models: first-order autoregressive, compound symmetry, Toeplitz, and Toeplitz heterogeneous; the covariance structure that resulted in the smallest Akaike information criterion was selected. Model fit was assessed by visually judging the normality of studentized residuals. To attain normality, BHB and NEFA were log-transformed and square root-transformed, respectively; results are presented as back-transformed values. If the interaction between inflammatory status and sampling time was significant, comparisons at each sampling time point were adjusted post hoc using Tukey's test. Statistical significance was present when $P \leq 0.05$, and tendencies when $0.05<P \leq 0.10$.

\section{RESULTS}

\section{Descriptive Data}

A total of 233 cows without clinical diseases in the first $14 \mathrm{~d}$ after parturition were included in the statistical analyses. Of note, 99 cows $(42.5 \%)$ had a haptoglobin concentration above the median threshold of the reference population at d 4 after parturition $(>0.49$ $\mathrm{g} / \mathrm{L})$. Of the 99 cows with elevated haptoglobin at d 4 , 59 still had elevated haptoglobin at d 7 after parturition $(>0.35 \mathrm{~g} / \mathrm{L})$. Therefore, cows with eHp represented $25.3 \%(\mathrm{n}=59)$ of the data set, and cows without eHp represented $74.7 \%(\mathrm{n}=174)$. Median plasma haptoglobin concentrations for cows without eHp on d 4 and 7 after parturition were $0.29 \mathrm{~g} / \mathrm{L}$ (interquartile range $=0.25$ to 1.21 ), and $0.26 \mathrm{~g} / \mathrm{L}$ (interquartile range $=$ 0.22 to 1.04 ), respectively. Median plasma haptoglobin concentrations for cows with eHp on d 4 and 7 after parturition were $1.23 \mathrm{~g} / \mathrm{L}$ (interquartile range $=0.66$ to 2.28 ) and $1.01 \mathrm{~g} / \mathrm{L}$ (interquartile range $=0.51$ to 1.75 ), respectively (Figure 1). Descriptive data by inflammatory status for parity, calving season, BCS, incidence of mastitis and culling between 15 and 60 DIM, and Metricheck scores on d 4, 7, and 10 after parturition are presented in Table 1 . Notably, $78.0 \%$ of the cows with eHp calved in the warmer season; the proportion 
Table 1. Distribution of cows by parity, BCS category, calving season, mastitis incidence, culling, and Metricheck scores on d 4, 7, and 10 in a cohort study of systemic inflammation in multiparous, postpartum Jersey cows

\begin{tabular}{|c|c|c|c|c|}
\hline \multirow[b]{3}{*}{ Item } & \multicolumn{4}{|c|}{$\begin{array}{c}\text { Systemic inflammation } \\
\text { categorization }^{1}\end{array}$} \\
\hline & \multicolumn{2}{|c|}{$\begin{array}{l}\text { Without eHp } \\
\quad(\mathrm{n}=174)\end{array}$} & \multicolumn{2}{|c|}{$\begin{array}{l}\text { With eHp } \\
(\mathrm{n}=59)\end{array}$} \\
\hline & $\mathrm{n}$ & $\%$ & $\mathrm{n}$ & $\%$ \\
\hline \multicolumn{5}{|l|}{ Parity } \\
\hline 2 & 71 & 40.8 & 20 & 33.9 \\
\hline$\geq 3$ & 103 & 59.2 & 39 & 66.1 \\
\hline \multicolumn{5}{|l|}{$\overline{\mathrm{BCS}}$} \\
\hline$\leq 2.75$ & 24 & 13.8 & 7 & 11.9 \\
\hline 3.0 to 3.5 & 129 & 74.1 & 43 & 72.9 \\
\hline$\geq 3.75$ & 21 & 12.1 & 9 & 15.3 \\
\hline \multicolumn{5}{|c|}{ Calving season $^{2}$} \\
\hline Cool & 99 & 56.9 & 13 & 22.0 \\
\hline Warm & 75 & 43.1 & 46 & 78.0 \\
\hline \multicolumn{5}{|l|}{ Mastitis $^{3}$} \\
\hline No & 156 & 89.7 & 52 & 88.1 \\
\hline Yes & 18 & 10.3 & 7 & 11.9 \\
\hline \multicolumn{5}{|l|}{ Culled $^{3}$} \\
\hline No & 164 & 94.3 & 55 & 93.2 \\
\hline Yes & 10 & 5.7 & 4 & 6.8 \\
\hline \multicolumn{5}{|c|}{ Metricheck score d $4^{4}$} \\
\hline 0 & 4 & 2.3 & 5 & 8.5 \\
\hline 1 & 62 & 35.6 & 16 & 27.1 \\
\hline 2 & 68 & 39.1 & 21 & 35.6 \\
\hline 3 & 16 & 9.2 & 7 & 11.9 \\
\hline 4 & 24 & 13.8 & 10 & 16.9 \\
\hline \multicolumn{5}{|c|}{ Metricheck score d $7^{4}$} \\
\hline 0 & 12 & 6.9 & 3 & 5.1 \\
\hline 1 & 73 & 42.0 & 19 & 32.2 \\
\hline 2 & 52 & 29.9 & 25 & 42.4 \\
\hline 3 & 21 & 12.1 & 8 & 13.6 \\
\hline 4 & 16 & 9.2 & 4 & 6.8 \\
\hline \multicolumn{5}{|c|}{ Metricheck score d $10^{4}$} \\
\hline 0 & 3 & 1.7 & 3 & 5.1 \\
\hline 1 & 48 & 27.6 & 8 & 13.6 \\
\hline 2 & 61 & 35.1 & 20 & 33.9 \\
\hline 3 & 40 & 23.0 & 16 & 27.1 \\
\hline 4 & 22 & 12.6 & 12 & 20.3 \\
\hline
\end{tabular}

${ }^{1}$ Cows with plasma haptoglobin concentrations greater than the median values from the reference population on both $\mathrm{d} 4(0.49 \mathrm{~g} / \mathrm{L})$ and $7(0.35 \mathrm{~g} / \mathrm{L})$ after parturition were considered to have continually elevated haptoglobin concentrations (with $\mathrm{eHp}$ ). Cows with plasma haptoglobin concentrations lower than or equal to the median values from the reference population on d 4 or 7 after parturition were considered not to have continually elevated haptoglobin concentrations (without eHp).

${ }^{2}$ Calving season was categorized to represent cows that calved in warmer months (July 16 to September 22, 2018) and cooler months (September 23 to December 9, 2018).

${ }^{3}$ Mastitis and culling that occurred between 15 and 60 DIM.

${ }^{4}$ Metricheck (Simcro, Hamilton, New Zealand) exams performed at d 4, 7 , and 10 after parturition. Scores: $0=$ no discharge; $1=$ clear mucoid discharge with no smell; $2=$ cloudy and mucoid discharge with no smell; $3=$ mucopurulent discharge with $<50 \%$ pus and no smell; 4 $=$ mucopurulent discharge ranging in white, yellowish to red-brownish color with $\geq 50 \%$ pus and not fetid. of those without eHp calving in the cooler $(56.9 \%)$ and warmer $(43.1 \%)$ months followed a more even distribution.

\section{Mineral, Protein, and Energy Balance Markers}

Systemic inflammation was significantly associated with mean plasma Ca concentrations $(P=0.04$; Table $2)$. Other variables controlled for in the model were sampling time $(P<0.001)$, parity $(P=0.13)$, and season $(P=0.38)$. Cows with eHp had a mean plasma Ca concentration of $2.03 \pm 0.02 \mathrm{mmol} / \mathrm{L}$, and cows without eHp had a mean of $2.07 \pm 0.01 \mathrm{mmol} / \mathrm{L}$.

Systemic inflammation was not associated with BHB concentrations $(P=0.84)$. Cows with and without eHp had mean plasma BHB concentrations of $0.71 \pm$ 0.04 and $0.71 \pm 0.02 \mathrm{mmol} / \mathrm{L}$, respectively. Similarly, systemic inflammation was not associated with plasma NEFA $(P=0.73)$; cows with and without eHp had mean plasma NEFA concentrations of $0.44 \pm 0.02$ and $0.43 \pm 0.01 \mathrm{mmol} / \mathrm{L}$, respectively. Systemic inflammation was not associated with glucose concentrations $(P$ $=0.83)$.

We found an interaction between systemic inflammation and time for the fructosamine $(P=0.02)$, albumin $(P=0.03)$, and urea $(P<0.001)$ models (Figure 2$)$. Controlling for parity $(P=0.03)$ and calving season $(P<0.001)$, cows with eHp had reduced plasma fructosamine concentrations on d $7(172.9 \pm 3.30$ vs. 186.7 $\pm 1.87 \mu \mathrm{mol} / \mathrm{L} ; P=0.01)$ and $\mathrm{d} 10$ after parturition

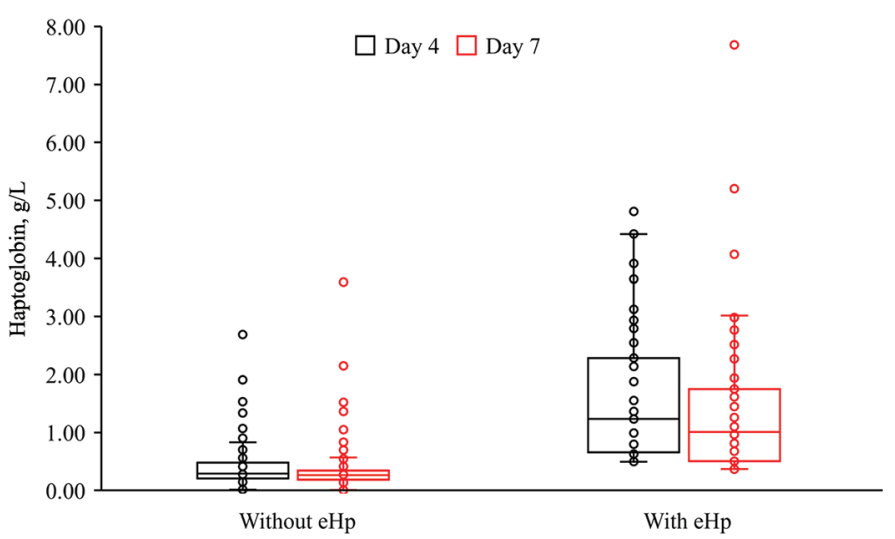

Figure 1. Box-and-whisker plots of plasma haptoglobin on d 4 and 7 after parturition for cows with or without continually elevated haptoglobin (eHp) in a cohort study of 233 multiparous Jersey cows. Cows with $\mathrm{eHp}(\mathrm{n}=59)$ had plasma haptoglobin concentrations greater than the median values from the reference population on both $\mathrm{d} 4$ $(0.49 \mathrm{~g} / \mathrm{L})$ and $7(0.35 \mathrm{~g} / \mathrm{L})$ after parturition. Cows without eHp $(\mathrm{n}=$ 174) had plasma haptoglobin concentrations lower than or equal to the median values from the reference population on d 4 or 7 after parturition. Each box plot illustrates the 50th percentile (median; line within the box), the 25th and 75th percentiles (lower and upper limits of the box), and the 10th and 90th percentiles (whiskers). 
Table 2. Summary of linear mixed models evaluating the association of early-lactation systemic inflammatory status with mineral, energy, and protein markers in the first 2 wk after parturition, milk production in the first 60 DIM, and rectal temperatures evaluated at 4, 7, and 10 DIM in a cohort study of 233 multiparous Jersey cows

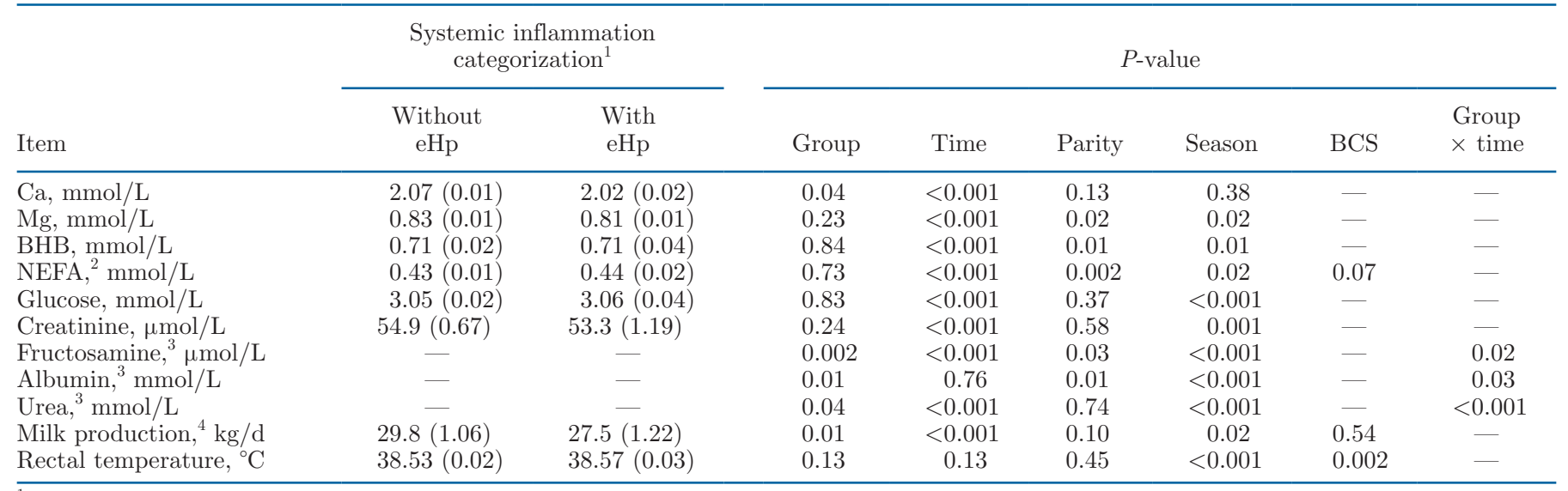

${ }^{1}$ Results presented are LSM (SEM). Cows with plasma haptoglobin concentrations greater than the median values from the reference population on both d $4(0.49 \mathrm{~g} / \mathrm{L})$ and $7(0.35 \mathrm{~g} / \mathrm{L})$ after parturition were considered to have continually elevated haptoglobin concentrations (with eHp). Cows with plasma haptoglobin concentrations lower than or equal to the median values from the reference population on $\mathrm{d} 4$ or 7 after parturition were considered not to have continually elevated haptoglobin concentrations (without eHp).

${ }^{2}$ Nonesterified fatty acids.

${ }^{3}$ Least squares means omitted due to a significant group $\times$ time interaction. Data are presented graphically in Figure 2 .

${ }^{4}$ The milk production model accounted for the effect of clinical mastitis diagnosed between 15 and 60 DIM $(P=0.001)$ and culling between 15 and 60 DIM $(P<0.001)$. Culled cows contributed to the repeated measures analysis with milk weights that happened before the culling event.

$(169.0 \pm 3.44$ vs. $183.9 \pm 1.95 \mu \mathrm{mol} / \mathrm{L} ; P=0.003) \mathrm{com}-$ pared to those without eHp, respectively. We observed a similar response for plasma albumin after controlling for parity $(P=0.01)$ and season $(P<0.001)$ : cows with eHp tended to have reduced plasma albumin concentrations on $\mathrm{d} 7(2.96 \pm 0.05$ vs. $3.14 \pm 0.03 \mathrm{mmol} / \mathrm{L} ; P=$ $0.06)$ and $\mathrm{d} 10$ after parturition $(2.98 \pm 0.06$ vs. 3.18 $\pm 0.03 \mathrm{mmol} / \mathrm{L} ; P=0.06)$ compared to cows without eHp, respectively. Plasma urea concentrations were decreased on d 10 postpartum in cows with eHp (3.36 $\pm 0.11 \mathrm{mmol} / \mathrm{L})$ compared to those without eHp (3.83 $\pm 0.06 \mathrm{mmol} / \mathrm{L} ; P=0.01)$. Systemic inflammation was not associated with plasma creatinine concentrations $(P=0.24)$.

\section{Milk Yield and Rectal Temperature}

We found an association between systemic inflammation and milk production across the first $60 \mathrm{~d}$ of lactation $(P=0.01)$. The model accounted for the effects of calving season $(P=0.02)$, BCS $(P=0.54)$, clinical mastitis between 15 and 60 DIM $(P=0.001)$, culling between 15 and 60 DIM $(P<0.001)$, and the repeated effect of weekly milk test $(P<0.001$; Table 2$)$. Cows with eHp produced an average of $2.3 \pm 0.85 \mathrm{~kg} / \mathrm{d}$ less milk than cows without eHp.

Systemic inflammation was not associated with rectal temperatures evaluated on $\mathrm{d} 4,7$, and 10 postpartum $(P=0.13)$.

\section{DISCUSSION}

To better understand the effects of subclinical inflammation and resolution in postparturient cows, we performed a proof-of-concept study that retrospectively classified a cohort without clinical diseases in the first 2 wk after calving as those with prolonged, low-grade inflammation and those without; we classified the cohort based on continually elevated haptoglobin concentrations measured on d 4 and 7 after parturition. Our aims were to evaluate whether systemic inflammation was associated with milk production, mineral, protein, and energy metabolites. It is important to note that the metabolites evaluated in the present study were collected both before and after the time points used to categorize the cows. Cows with eHp had reduced concentrations of fructosamine, albumin, and urea in a time-dependent manner across the first 14 DIM. They also had reduced plasma Ca concentration in the first 14 DIM, and they produced less milk in the first 60 DIM than cows without eHp. We did not find associations between systemic inflammation and plasma $\mathrm{Mg}$, BHB, NEFA, or glucose concentrations, and we found no differences in rectal temperatures evaluated on d 4 , 7, and 10 postpartum.

Acute-phase proteins are produced by hepatocytes or peripheral tissues, and they play major roles in several aspects of the systemic reaction to inflammation (Ceciliani et al., 2012). After an inflammatory insult, 

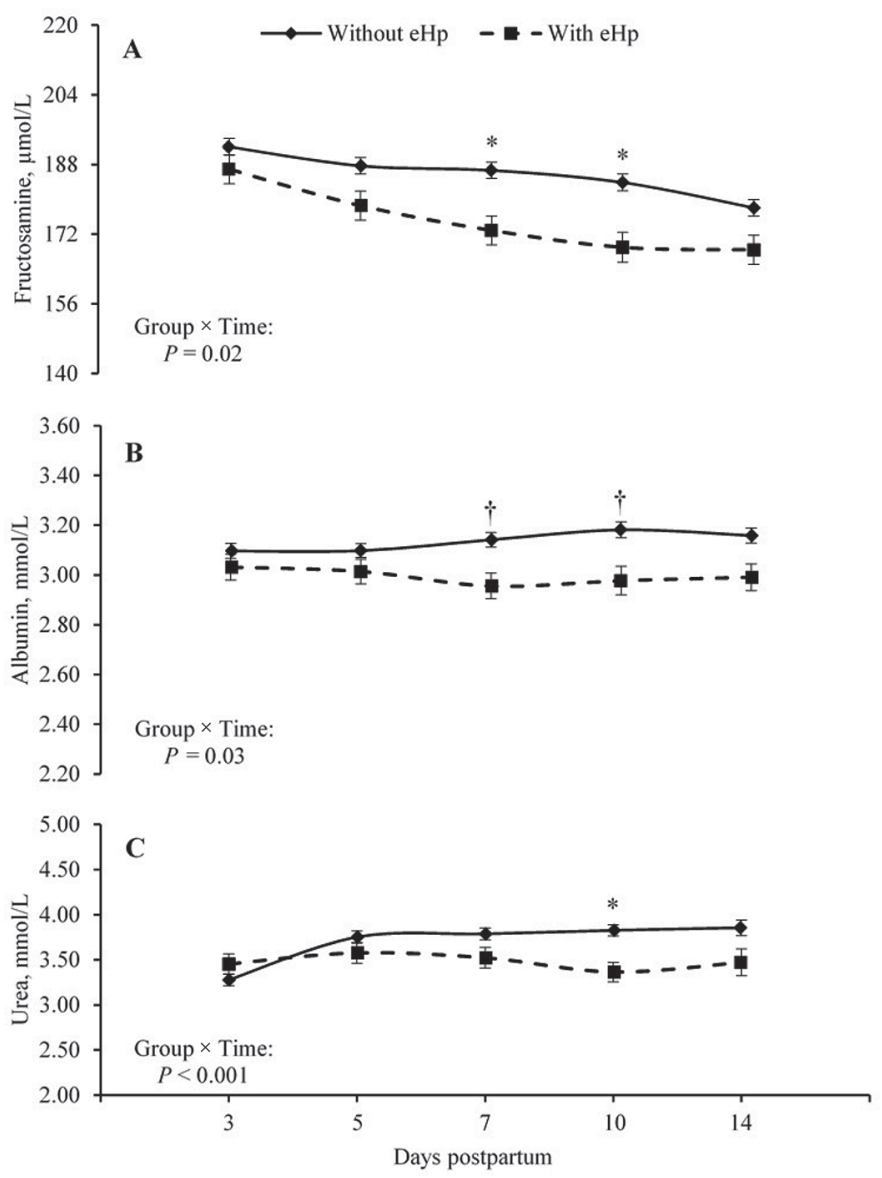

Figure 2. Postpartum plasma (A) fructosamine, (B) albumin, and (C) urea for cows with or without continually elevated haptoglobin (eHp) in a cohort study of 233 multiparous Jersey cows. Cows with eHp had plasma haptoglobin concentrations greater than the median values from the reference population on both $\mathrm{d} 4(0.49 \mathrm{~g} / \mathrm{L})$ and 7 $(0.35 \mathrm{~g} / \mathrm{L})$ after parturition. Cows without eHp had plasma haptoglobin concentrations lower than or equal to the median values from the reference population on d 4 or 7 after parturition. ${ }^{*} P \leq 0.05 ; \dagger 0.05<$ $P \leq 0.10$. Error bars represent SEM.

an increase in positive or a decrease in negative acutephase reactants occurs. Haptoglobin is a positive acutephase protein associated with impaired liver activity (Trevisi et al., 2010, 2013) and functionality (Trevisi et al., 2012) indexes in early-postpartum dairy cows; in other words, it can negatively affect the liver's capacity to adequately perform the metabolism of nutrients such as glucose, amino acids, and fatty acids. Increased postpartum concentrations of haptoglobin have been associated with calving assistance (Pohl et al., 2015), retained placenta (Dervishi et al., 2016), metritis (Huzzey et al., 2009), ketosis (Abuajamieh et al., 2016), displaced abomasum (Stengärde et al., 2010), lower resumption of postpartum ovarian activity (Krause et al., 2014), and decreased risk of conception by 150 DIM (Huzzey et al.,
2015). Although it is a nonspecific reactor associated with some illnesses, haptoglobin can be considered a relevant marker for characterizing inflammatory status, because it is at least not affected by the genetic group of cows (Banos et al., 2013).

Our results demonstrate that cows with eHp produced $2.3 \mathrm{~kg}$ milk/d less in the first 60 DIM than cows without eHp. Other studies have shown a negative association between inflammatory status and milk production, although it is not clear whether and by how much clinical diseases could have confounded those associations. Huzzey et al. (2015) found that for each increase in plasma haptoglobin concentration of $1 \mathrm{~g} / \mathrm{L}$ in the first week postpartum, a decrease of $464 \mathrm{~kg}$ of milk $(95 \%$ confidence interval $=-732$ to $-195 \mathrm{~kg})$ in a 305-d projected lactation occurred; however, how much clinical diseases affected the cohort of cows in that study is also not known, because it was not specified. McCarthy et al. (2016) found a quadratic association between haptoglobin concentration categorized in quartiles with ECM and FCM in the first 9 wk of lactation; cows with clinical diseases were included in that study but, because of low incidences, disease data were presented only descriptively. Shin et al. (2018) described reduced milk production in the first 60 DIM of cows with haptoglobin concentrations higher than $100 \mu \mathrm{g} / \mathrm{mL}(0.1 \mathrm{~g} / \mathrm{L})$ measured in the first week postpartum; in that study, cows with elevated haptoglobin had more dystocia, retained placenta, metritis, and endometritis. Trevisi et al. (2012) and Trevisi et al. (2013) demonstrated a decrease in milk production for cows with low liver functionality and activity indexes in the first month of lactation; cows with a lower liver activity index had more postpartum diseases in both studies. In our study, we selectively removed cows with any clinical disorder in the first 2 wk of parturition to better isolate the effects of subclinical inflammation status (i.e., elevated haptoglobin concentrations not directly associated with clinical diseases). Moreover, we attempted to adopt a categorization scheme of systemic inflammation based on haptoglobin concentrations that would more likely be reflective of an impaired anti-inflammatory response in the postpartum period by analyzing samples at $d$ 4 and 7 after parturition [i.e., after haptoglobin peak concentration, which on average occurs at $72 \mathrm{~h}$ postcalving, and allowing for a haptoglobin decline period of $3 \mathrm{~d}$ to contain the serum half-life decay of $46 \mathrm{~h}$; (Salonen et al., 1996)]. Although our categorization scheme of systemic inflammation was scientifically reasoned in the context of our current knowledge, it was not exempt from errors and was somewhat subjective. We do not know whether the haptoglobin thresholds we used were appropriate for identifying cows with a 
subclinical inflammatory state. We used haptoglobin limits based on median concentrations of the reference population (i.e., established when considering diseased cows in the data set) to adopt thresholds that could reflect slightly increased haptoglobin concentrations at the investigated time points; this presumptively allowed us to differentiate a group of cows with a less-thanoptimal postpartum inflammatory state. At present, we do not know whether haptoglobin is a sensitive marker for characterizing a prolonged inflammatory state and whether our categorization based on 2 sampling time points was an accurate one. We emphasize the need for more studies that can properly contrast how other markers of systemic inflammation may be used to identify cows transitioning to a chronic inflammatory process and if simplified sampling strategies can be adopted to accurately identify this group of cows. Therefore, we do not encourage the application of the same sampling strategy or reference limits used in this study to define a prolonged postpartum inflammatory state. Our main goal was to demonstrate a concept and possibly stimulate more studies in this area to more properly translate this knowledge into field applications.

The Ca dynamics in the early lactation period (McArt and Neves, 2020) and the association of Ca with performance and health outcomes depend on the DIM of assessment and parity (Neves et al., 2018). We found that cows with eHp had decreased Ca concentrations during the first 14 DIM, although the difference seemed small (i.e., $0.05 \mathrm{mmol} / \mathrm{L}$ ) and an interaction between inflammatory status and sampling time was not present. However, we believe that this finding corroborated the characterization of a subclinical inflammatory state in our study. Parturition is a high-risk period for immune challenges, during which considerable adaptations in metabolism occur to support lactation. In a lipopolysaccharide challenge model using dairy cows, immune activation has been shown to decrease circulating Ca (Horst et al., 2020), suggesting that an acute inflammatory process can negatively affect the metabolic adaptation of dairy cows in the transition period. Using the liver activity index as the main parameter, Bertoni et al. (2008) found that cows with higher indexes had increased concentrations of $\mathrm{Ca}$ and $\mathrm{Mg}$ in the postpartum period; this could be suggestive of an improved metabolic adaptation process. In our study, we found no association between systemic inflammatory status and plasma $\mathrm{Mg}$ concentration.

We found no association between systemic inflammatory status and the energy balance markers evaluated (NEFA, BHB, and glucose). Nightingale et al. (2015) found no association between NEFA or BHB with increased haptoglobin concentrations measured in the first week postpartum in a clinically healthy cohort of cows. Although energy metabolites and haptoglobin concentrations can be associated, increased plasma NEFA and BHB are more pronounced in cows diagnosed with clinical disorders after calving (Huzzey et al., 2011; Shin et al., 2018). For instance, cows with ketosis have increased concentrations of acute-phase proteins, such as haptoglobin, ceruloplasmin, and serum amyloid A (Abuajamieh et al., 2016; Li et al., 2018; Mezzetti et al., 2019). Glucose requirements in a model of acute inflammation were greatly increased (Kvidera et al., 2017). Upregulation of TNF- $\alpha$ is associated with chronic inflammatory conditions such as type 2 diabetes in humans and has been shown to alter insulin action ex vivo (Hotamisligil et al., 1994; Popa et al., 2007). In lactating cows, repeated injections of TNF- $\alpha$ for $7 \mathrm{~d}$ (as an induction model of chronic inflammation) did not alter energy balance markers (Yuan et al., 2013). More observational studies are necessary to understand whether a more chronic, persistent inflammatory state is associated with negative energy balance in postpartum cows.

We found time-dependent associations of systemic inflammation with postpartum plasma albumin, fructosamine, and urea concentrations. Albumin is one of the major negative acute-phase reactants, and its concentration is associated with liver activity or functionality indexes (Trevisi et al., 2010; Trevisi et al., 2012). Fructosamine is a glycated protein formed mainly by a nonenzymatic reaction between glucose and albumin, and it is commonly used as a retrospective glycemic marker in patients with diabetes (Armbruster, 1987). Fructosamine seems to be a poor retrospective marker of glycemia in transition period dairy cows (Megahed et al., 2018), although there is evidence of an association between lower concentrations of fructosamine and increased postpartum inflammation and reduced DMI (Caré et al., 2018; Mammi et al., 2020). Therefore, we hypothesized that systemic inflammation would be associated with albumin and fructosamine in our study as well. Bertoni et al. (2008) found a negative correlation between haptoglobin and albumin, supporting our results. Caré et al. (2018) demonstrated that cows with low fructosamine concentrations measured after 14 DIM had higher haptoglobin concentrations in the first 2 wk postpartum, and lower DMI in the 3 previous weeks before the haptoglobin measurement. Thus, lower concentrations of fructosamine in the first 10 DIM, as found in our study, can be a consequence of either lower DMI, an increased inflammatory response, or both. In our study, Pearson correlation coefficients between albumin and fructosamine concentrations assessed on each day in the postpartum period (i.e., 3, 5, 7, 10, and 
$14 \mathrm{~d}$ after parturition) was always high $(r=0.80$ to 0.84; data not shown). Therefore, the clinical utility of fructosamine measurements over albumin to help characterize systemic reaction to inflammation was likely negligible for our results. Larger observational studies are necessary to demonstrate whether fructosamine can offer any advantage over albumin for characterizing postpartum systemic inflammation. Furthermore, we hypothesize that the reduced urea concentrations we found at d 10 after parturition in cows with eHp was likely a result of reduced DMI because of lower rumen nitrogen supply (i.e., feed consumption) and decreased hepatic urea synthesis (Lapierre and Lobley, 2001).

After removing cows with diagnosed clinical disorders in the first 14 DIM, we did not expect to find a difference in rectal temperatures between cows with and without eHp; this was confirmed by our results. However, interestingly, a higher proportion of cows with eHp calved during the warmer months, and we believe that heat stress may have influenced this finding. It is known that heat stress reduces DMI and, consequently, milk production (West, 2003; Rhoads et al., 2009). In pigs, heat stress has been linked to reduced intestinal integrity (a leaky-gut state), allowing LPS translocation from the gastrointestinal tract to systemic circulation (Pearce et al., 2013). In dairy cows, induction of heat stress reduced jejunal barrier integrity and increased mucosal immune cell infiltration (an indication of immune activation; Koch et al., 2019). It is possible that heat stress was a contributing factor to a prolonged inflammatory state in our study. More controlled experiments and field studies are warranted to evaluate the effect of heat stress on systemic inflammation (both as a promoter of inflammation and as a hindering factor in the resolution of inflammation) in early-postpartum cows. For the herd in our study, cooling was provided only in the holding pen and parlor areas; the home pens provided only shaded areas and had no water sprinkling system mounted over the feed bunk.

Several questions remain to be answered after this proof-of-concept study that will require a greater number of cows and herds included so it can be properly addressed. For instance, more studies are necessary to characterize persistent inflammation while contrasting it with simpler sampling approaches that can correctly classify this group of cows; this should facilitate the translation of knowledge to herd-monitoring programs. Only after prolonged or persistent inflammatory status can be more clearly described we will be able to more appropriately study potential anti-inflammatory rescue therapies. In addition, the evaluation of associations between prolonged inflammation and metrics of greater economic importance such as reproductive efficiency and 305-d lactation performance are needed.

\section{CONCLUSIONS}

Our study demonstrated that evaluating plasma haptoglobin concentrations ( $3 \mathrm{~d}$ apart toward the end of the first week of parturition) to classify clinically healthy cows with subclinical and prolonged systemic inflammation was associated with reduced concentrations of albumin and fructosamine in a time-dependent manner. Moreover, continually elevated haptoglobin was associated with reduced plasma Ca concentrations in the first 2 wk after calving and lower milk production in the first $60 \mathrm{~d}$ of lactation. More studies are necessary to demonstrate the mechanisms by which prolonged, low-grade inflammation results in lower milk production, and whether this inflammatory state impairs the entire lactation period.

\section{ACKNOWLEDGMENTS}

We gratefully acknowledge Maria Luiza Celestino and Diego Poit for their invaluable help during data collection. The authors thank the producer and employees for their great support during the study. The authors have not stated any conflicts of interest.

\section{REFERENCES}

Abuajamieh, M., S. K. Kvidera, M. V. S. Fernandez, A. Nayeri, N. C. Upah, E. A. Nolan, S. M. Lei, J. M. DeFrain, H. B. Green, K. M. Schoenberg, W. E. Trout, and L. H. Baumgard. 2016. Inflammatory biomarkers are associated with ketosis in periparturient Holstein cows. Res. Vet. Sci. 109:81-85. https://doi.org/10.1016/ j.rvsc.2016.09.015.

Armbruster, D. A. 1987. Fructosamine: Structure, analysis, and clinical usefulness. Clin. Chem. 33:2153-2163. https://doi.org/10 $.1093 /$ clinchem/33.12.2153.

Banos, G., E. Wall, M. P. Coffey, A. Bagnall, S. Gillespie, G. C. Russell, and T. N. McNeilly. 2013. Identification of immune traits correlated with dairy cow health, reproduction and productivity. PLoS One 8:e65766. https://doi.org/10.1371/journal.pone .0065766 .

Bertoni, G., E. Trevisi, X. Han, and M. Bionaz. 2008. Effects of inflammatory conditions on liver activity in puerperium period and consequences for performance in dairy cows. J. Dairy Sci. 91:33003310. https://doi.org/10.3168/jds.2008-0995.

Bradford, B. J., L. K. Mamedova, J. E. Minton, J. S. Drouillard, and B. J. Johnson. 2009. Daily injection of tumor necrosis factor- $\alpha$ increases hepatic triglycerides and alters transcript abundance of metabolic genes in lactating dairy cattle. J. Nutr. 139:1451-1456. https://doi.org/10.3945/jn.109.108233.

Bradford, B. J., K. Yuan, J. K. Farney, L. K. Mamedova, and A. J. Carpenter. 2015. Invited review: Inflammation during the transition to lactation: New adventures with an old flame. J. Dairy Sci. 98:6631-6650. https://doi.org/10.3168/jds.2015-9683.

Caré, S., E. Trevisi, A. Minuti, A. Ferrari, J. J. Loor, and L. Calamari. 2018. Plasma fructosamine during the transition period and its relationship with energy metabolism and inflammation biomarkers in dairy cows. Livest. Sci. 216:138-147. https://doi.org/10.1016/j livsci.2018.08.003

Ceciliani, F., J. J. Ceron, P. D. Eckersall, and H. Sauerwein. 2012. Acute phase proteins in ruminants. J. Proteomics 75:4207-4231. https://doi.org/10.1016/j.jprot.2012.04.004. 
Challis, J. R., C. J. Lockwood, L. Myatt, J. E. Norman, J. F. Strauss III, and F. Petraglia. 2009. Inflammation and pregnancy. Reprod. Sci. 16:206-215. https://doi.org/10.1177/1933719108329095.

de Oliveira, E. B., F. Cunha, R. Daetz, C. C. Figuereido, R. C. Chebel, J. E. Santos, C. A. Risco, K. C. Jeong, V. S. Machado, and K. N. Galvão. 2020. Using chitosan microparticles to treat metritis in lactating dairy cows. J. Dairy Sci. 103:7377-7391. https://doi.org/ 10.3168 /jds.2019-18028.

Dervishi, E., G. Zhang, D. Hailemariam, S. M. Dunn, and B. N. Ametaj. 2016. Occurrence of retained placenta is preceded by an inflammatory state and alterations of energy metabolism in transition dairy cows. J. Anim. Sci. Biotechnol. 7:26. https://doi.org/10 .1186/s40104-016-0085-9.

Farney, J. K., L. K. Mamedova, J. F. Coetzee, B. KuKanich, L. M. Sordillo, S. K. Stoakes, J. E. Minton, L. C. Hollis, and B. J. Bradford. 2013. Anti-inflammatory salicylate treatment alters the metabolic adaptations to lactation in dairy cattle. Am. J. Physiol. Regul. Integr. Comp. Physiol. 305:R110-R117. https://doi.org/10 .1152/ajpregu.00152.2013.

Ferguson, J. D., D. T. Galligan, and N. Thomsen. 1994. Principal descriptors of body condition score in Holstein cows. J. Dairy Sci. 77:2695-2703. https://doi.org/10.3168/jds.S0022-0302(94)77212 $-\mathrm{X}$.

Horst, E. A., E. J. Mayorga, M. Al-Qaisi, M. A. Abeyta, S. L. Portner, C. S. McCarthy, B. M. Goetz, S. K. Kvidera, and L. H. Baumgard. 2020. Effects of maintaining eucalcemia following immunoactivation in lactating Holstein dairy cows. J. Dairy Sci. 103:7472-7486. https://doi.org/10.3168/jds.2020-18268.

Hotamisligil, G. S., D. L. Murray, L. N. Choy, and B. M. Spiegelman. 1994. Tumor necrosis factor alpha inhibits signaling from the insulin receptor. Proc. Natl. Acad. Sci. USA 91:4854-4858. https://doi .org/10.1073/pnas.91.11.4854.

Huzzey, J. M., T. F. Duffield, S. J. LeBlanc, D. M. Veira, D. M. Weary, and M. A. G. von Keyserlingk. 2009. Short communication: Haptoglobin as an early indicator of metritis. J. Dairy Sci. 92:621-625. https://doi.org/10.3168/jds.2008-1526.

Huzzey, J. M., S. Mann, D. V. Nydam, R. J. Grant, and T. R. Overton. 2015. Associations of peripartum markers of stress and inflammation with milk yield and reproductive performance in Holstein dairy cows. Prev. Vet. Med. 120:291-297. https://doi.org/10.1016/ j.prevetmed.2015.04.011.

Huzzey, J. M., D. V. Nydam, R. J. Grant, and T. R. Overton. 2011. Associations of prepartum plasma cortisol, haptoglobin, fecal cortisol metabolites, and nonesterified fatty acids with postpartum health status in Holstein dairy cows. 2011. J. Dairy Sci. 94:5878 5889. https://doi.org/10.3168/jds.2010-3391.

Koch, F., U. Thom, E. Albrecht, R. Weikard, W. Nolte, B. Kuhla, and C. Kuehn. 2019. Heat stress directly impairs gut integrity and recruits distinct immune cell populations into the bovine intestine. Proc. Natl. Acad. Sci. USA 116:10333-10338. https://doi.org/10 $.1073 /$ pnas. 1820130116.

Krause, A. R. T., L. F. M. Pfeifer, P. Montagner, M. M. Weschenfelder, E. Schwegler, M. E. Lima, E. G. Xavier, C. C. Brauner, E. Schmitt, F. A. B. Del Pino, C. F. Martins, M. N. Correa, and A. Schneider. 2014. Associations between resumption of postpartum ovarian activity, uterine health and concentrations of metabolites and acute phase proteins during the transition period in Holstein cows. Anim. Reprod. Sci. 145:8-14. https://doi.org/10.1016/j .anireprosci.2013.12.016.

Kvidera, S. K., E. A. Horst, M. Abuajamieh, E. J. Mayorga, M. V. Sanz Fernandez, and L. H. Baumgard. 2017. Glucose requirements of an activated immune system in lactating Holstein cows. J. Dairy Sci. 100:2360-2374. https://doi.org/10.3168/jds.2016-12001.

Lapierre, H., and G. E. Lobley. 2001. Nitrogen recycling in the ruminant: A review. J. Dairy Sci. 84:E223-E236. https://doi.org/10 .3168/jds.S0022-0302(01)70222-6.

Li, C., S. Dai, J. Lu, B. Zhao, J. Wang, P. Li, Z. Wu, Y. Mu, C. Feng, and Q. Dong. 2018. Methylglyoxal: A newly detected and potentially harmful metabolite in the blood of ketotic dairy cows. J. Dairy Sci. 101:8513-8523. https://doi.org/10.3168/jds.2018-14448.
Machado, V. S., M. L. Celestino, E. B. Oliveira, F. S. Lima, M. A. Ballou, and K. N. Galvão. 2020. The association of cow-related factors assessed at metritis diagnosis with metritis cure risk, reproductive performance, milk yield, and culling for untreated and ceftiofurtreated dairy cows. J. Dairy Sci. 103:9261-9276. https://doi.org/ $10.3168 /$ jds. $2020-18643$.

Makimura, S., and N. Suzuki. 1982. Quantitative determination of bovine serum haptoglobin and its elevation in some inflammatory diseases. Nihon Juigaku Zasshi 44:15-21. https://doi.org/10.1292/ jvms1939.44.15.

Mammi, L. M. E., D. Cavallini, M. Fustini, I. Fusaro, M. Giammarco, A. Formigoni, and A. Palmonari. 2020. Calving difficulty influences rumination time and inflammatory profile in Holstein dairy cows. J. Dairy Sci. https://doi.org/10.3168/jds.2020-18867. In press.

McArt, J. A. A., and R. C. Neves. 2020. Association of transient, persistent, or delayed subclinical hypocalcemia with early lactation disease, removal, and milk yield in Holstein cows. J. Dairy Sci. 103:690-701. https://doi.org/10.3168/jds.2019-17191.

McCarthy, M. M., T. Yasui, M. J. B. Felippe, and T. R. Overton. 2016. Associations between the degree of early lactation inflammation and performance, metabolism, and immune function in dairy cows. J. Dairy Sci. 99:680-700. https://doi.org/10.3168/jds.2015-9694.

Megahed, A. A., M. W. H. Hiew, and P. D. Constable. 2018. Clinical utility of plasma fructosamine concentration as a hypoglycemic biomarker during early lactation in dairy cattle. J. Vet. Intern. Med. 32:846-852. https://doi.org/10.1111/jvim.15049.

Mezzetti, M., A. Minuti, F. Piccioli-Cappelli, M. Amadori, M. Bionaz, and E. Trevisi. 2019. The role of altered immune function during the dry period in promoting the development of subclinical ketosis in early lactation. J. Dairy Sci. 102:9241-9258. https://doi.org/10 .3168/jds.2019-16497.

Neves, R. C., B. M. Leno, K. D. Bach, and J. A. A. McArt. 2018. Epidemiology of subclinical hypocalcemia in early-lactation Holstein dairy cows: The temporal associations of plasma calcium concentration in the first 4 days in milk with disease and milk production. J. Dairy Sci. 101:9321-9331. https://doi.org/10.3168/ jds.2018-14587.

Nightingale, C. R., M. D. Sellers, and M. A. Ballou. 2015. Elevated plasma haptoglobin concentrations following parturition are associated with elevated leukocyte responses and decreased subsequent reproductive efficiency in multiparous Holstein dairy cows. Vet. Immunol. Immunopathol. 164:16-23. https://doi.org/10.1016/j .vetimm.2014.12.016.

Pearce, S. C., V. Mani, R. L. Boddicker, J. S. Johnson, T. E. Weber, J. W. Ross, R. P. Rhoads, L. H. Baumgard, and N. K. Gabler. 2013. Heat stress reduces intestinal barrier integrity and favors intestinal glucose transport in growing pigs. PLoS One 8:e70215. https://doi .org/10.1371/journal.pone.0070215.

Pohl, A., O. Burfeind, and W. Heuwieser. 2015. The associations between postpartum serum haptoglobin concentration and metabolic status, calving difficulties, retained fetal membranes, and metritis. J. Dairy Sci. 98:4544-4551. https://doi.org/10.3168/jds.2014-9181.

Popa, C., M. G. Netea, P. L. van Riel, J. W. van der Meer, and A. F. Stalenhoef. 2007. The role of TNF-alpha in chronic inflammatory conditions, intermediary metabolism, and cardiovascular risk. J. Lipid Res. 48:751-762. https://doi.org/10.1194/jlr.R600021 -JLR200.

Rhoads, M. L., R. P. Rhoads, M. J. VanBaale, R. J. Collier, S. R. Sanders, W. J. Weber, B. A. Crooker, and L. H. Baumgard. 2009. Effects of heat stress and plane of nutrition on lactating Holstein cows: I. Production, metabolism, and aspects of circulating somatotropin. J. Dairy Sci. 92:1986-1997. https://doi.org/10.3168/ jds.2008-1641.

Salonen, M., J. Hirvonen, S. Pyörälä, S. Sankari, and M. Sandholm. 1996. Quantitative determination of bovine serum haptoglobin in experimentally induced Escherichia coli mastitis. Res. Vet. Sci. 60:88-91. https://doi.org/10.1016/s0034-5288(96)90138-1.

Serhan, C. N., and J. Savill. 2005. Resolution of inflammation: The beginning programs the end. Nat. Immunol. 6:1191-1197. https:// doi.org/10.1038/ni1276. 
Shin, D. H., J. K. Jeong, I. S. Choi, S. H. Moon, S. C. Lee, H. G. Kang, S. B. Park, and I. H. Kim. 2018. Associations between serum haptoglobin concentration and peri- and postpartum disorders, milk yield, and reproductive performance in dairy cows. Livest. Sci. 213:14-18. https://doi.org/10.1016/j.livsci.2018.04.015.

Stengärde, L., K. Holtenius, M. Tråvén, J. Hultgren, R. Niskanen, and U. Emanuelson. 2010. Blood profiles in dairy cows with displaced abomasum. J. Dairy Sci. 93:4691-4699. https://doi.org/10.3168/ jds.2010-3295.

Trevisi, E., M. Amadori, S. Cogrossi, E. Razzuoli, and G. Bertoni. 2012. Metabolic stress and inflammatory response in high-yielding, periparturient dairy cows. Res. Vet. Sci. 93:695-704. https://doi .org/10.1016/j.rvsc.2011.11.008.

Trevisi, E., G. Bertoni, R. Lombardelli, and A. Minuti. 2013. Relation of inflammation and liver function with the plasma cortisol response to adrenocorticotropin in early lactating dairy cows. J. Dairy Sci. 96:5712-5722. https://doi.org/10.3168/jds.2012-6375.

Trevisi, E., A. Zecconi, G. Bertoni, and R. Piccinini. 2010. Blood and milk immune and inflammatory profiles in periparturient dairy cows showing a different liver activity index. J. Dairy Res. 77:310317. https://doi.org/10.1017/S0022029910000178.

van Engelen, E., M. W. de Groot, V. N. Breeveld-Dwarkasing, M. E. Everts, G. C. van der Weyden, M. A. Taverne, and V. P. Rutten. 2009. Cervical ripening and parturition in cows are driven by a cascade of pro-inflammatory cytokines. Reprod. Domest. Anim. 44:834-841. https://doi.org/10.1111/j.1439-0531.2008.01096.x.

West, J. W. 2003. Effects of heat-stress on production in dairy cattle. J. Dairy Sci. 86:2131-2144. https://doi.org/10.3168/jds.S0022 $-0302(03) 73803-X$.

Yousef, M. K. 1985. Stress Physiology in Livestock. CRC Press, Boca Raton, FL.

Yuan, K., J. K. Farney, L. K. Mamedova, L. M. Sordillo, and B. J. Bradford. 2013. TNF- $\alpha$ altered inflammatory responses, impaired health and productivity, but did not affect glucose or lipid metabolism in early-lactation dairy cows. PLoS One 8:e80316. https://doi .org/10.1371/journal.pone.0080316. 